NBER WORKING PAPER SERIES

\title{
RECONSIDERING THE WORK DISINCENTIVE \\ EFFECTS OF SOCIAL SECURITY
}

Alan S. Bl inder

Roger H. Gordon

Donald E. Wise

Working Paper No. $\underline{562}$

\author{
NATIONAL BUREAU OF ECONOMIC RESEARCH \\ 1050 Massachusetts Avenue \\ Cambridge MA 02138 \\ October 1980
}

This paper is forthcoming in the National Tax Journal. We are grateful to Michael Ransom for research assistance, to two referees for useful suggestions; to Michael Hurd and Marc Robinson for pointing out an error in one of our computer programs; and to Peter Diamond, whose casual remark first persuaded us to look into this phenomenon. This research has been supported by the U.S. Department of Labor and the National Science Foundation. The views expressed herein are those of the authors, and not any of the organizations with which they are affiliated. The research reported here is part of the NBER's research program in Economic Fluctuations. 


\section{Reconsidering the Work Disincentive \\ Effects of Social Security}

\section{$\underline{\text { ABSTRACT }}$}

This paper shows that, contrary to commonly held views, the provisions of the social security law actually provide strong work incentives for older men. The reason is that, for most workers, higher current earnings lead to higher future social security benefits. These incentives have been particularly strong for workers under 65 years of age and, although they will be reduced somewhat when the 1977 amendments to the social security law become fully effective, they will remain substantial. The findings raise serious questions about recent econometric work attributing the decline in labor force participation rates of older men to the social security system.

Alan S. Blinder Koger H. Gordon

Department of Economics

Princeton University

Princeton, New Jersey 08544

(609) $452-4010$

(609) 452-4018
Donald E. Wise

Mathtech, Incorporated Princeton Junction Office Park Princeton, New Jersey 08540 


\section{Introduction}

Labor force participation rates of older men in the United States have declined significantly in recent decades. Among the factors that allegedly account for this phenomenon is the social security system, which has increased both in coverage and in generosity over the period. That social security should lead to earlier retirement seems in accord with common sense, and so is widely assumed. Furthermore, several recent econometric contributions have appeared to buttress this common as sumption. 1

Our purpose in this paper is a curmudgeonly one: to case doubt on the widespread view that social security provides significant work disincentives for older men. Our principal reason for raising doubts about the common sense view is a poorlyunderstood provision of the law which provides strong work incentives for most workers-incentives which in many cases are large enough to cancel out or even overwhelm the work disincentive effects of the earnings test.

The plan of the paper is as follows. Section 2 briefly describes and critically evaluates the conventional argument for why social security discourages labor supply. Section 3 explains in some detail the important aspect of the law that has hitherto mostly been ignored: the fact that current earnings can increase future social security benefits. Calculations based on the Longitudinal Retirement History Survey (LRHS) are presented to show that this effect is typically equivalent to a wage subsidy roughly equal in size to the tax rate of the earnings test. Section 4 offers somo concluding remarks, but our main message is both simple and important enough to be mentionod rifht at the outset. Social security certainly distorts labor-leisure choice, but not in any simple way. It may in fact induce some older workers to reduce their labor supply. But there must be many others who--if they understood the law properly--would be encouraged to work even more than they would in the absence of social security. 
2. Work Disincentives: The Conventional View

The conventional view that social security discourages the work effort of older workers is based on two perceived problems with the law. First, benefits are subject to an earnings test which implicitly taxes earnings beyond an exempt amount at a $50 \%$ marginal rate. Second, actuarial adjustments for those who defer benefits are believed to be insufficient, so the expected present value of social security benefits declines the longer one stays at work. We take up each of these in turn. The Earnings Test

The structure of the social security benefit formula is approximately as follows. Let $E=\left(e_{1}, e_{2}, \ldots, e_{T}\right)$, where $e_{i}$ is covered earnings $i$ years ago, be a vector describing an individual's earnings history; and let $X$ be a vector of relevant demographic characteristics such as marital status, number of dependent children, etc. The law defines a potential benefit $B=B(E, X){ }^{2}$ Once current sarnings, $e_{0}$, pass the exempt amount, $m$, benefits are reduced by $50 \phi$ for each dollar earned until they are completely exhausted. Thus the actual benefits received are equal to $B$ until earnings reach $m, B-.5\left(e_{0}-m\right)$ if $m<e_{0}<m+2 B$, and zero if earnings exceed $m+2 B$. The reduction in benefits as earnings rise in the range $m \leq e_{0} \leq m+2 B$ (the "earnings test") clearly provides a work disincentive. The budget constraint created by the earnings test is portrayed in Figure $\perp$ as abcde, where it is contrasted with the budget constraint that would prevail in the absence of social security benefits (ade). ${ }^{3}$ The vertical distance ab represents the benefits that are received at zero earnings. As earnings rise from zero to $\mathrm{m}$ there is no reduction in benefits, so the slope of the budget line is the wage net of payroll tax, denoted $w_{0}(l-t)$. At point $c$, the earnings test comes into play, so the slope of the budget line is reduced by $.5 \mathrm{w}_{0}$, and this continues to be the case until point $d$, where all benefits are exhausted. Thereafter, the budget constraint for 
individuals who receive social security benefits corresponds with that for individuals who do not (line segment de).

The potential work disincentive effects of the earnings test are obvious from Figure 1 and, indeed, we should not be surprised to find many people "bunched" at point $c .^{4}$ This is the basic indictment of the earnings test; but it is naive for several reasons. The first of these is well known: many individuals who select a point to the left of point $c$ receive an increase in their future benefits.

\section{Actuarial Adjustments}

The nature of the actuarial adjustment made to future social security benefits of individuals who have some of their benefits withheld depends on whether the individual is eligible for partial benefits (ages 62-64) or for full benefits (ages 65 and over).

For individuals aged 62-64, the intent of the law is to provide an actuarially fair increase in future benefits for those who forego current benefits. Let us consider what an actuarially fair adjustment, would mean in terms of the budget constraint of Figure 1. Individuals who elect not to draw the (partial) benefits for which they. are eligible (the height $a b$ ) would have their future benefits increased to compensate them for this loss on an actuarial basis. Thus consider an individual who chooses to work enough so as not to draw benefits at age 62 . With no actuarial offset, his net earnings would be $e_{0}(l-t)$, and he would accrue no future social security benefits. With a full actuarial offset, by contrast, he would receive $e_{0}(1-t)$, from his own earnings plus an increase in future social security benefits equal in actuarial present value to the benefits he gives up this year, $B$, making his total income ${ }_{0}(1-t)+B$. Thus his effective budget constraint would be parallel to line ade, and uniformly above it by an amount equal to $B$. This is shown in Figure 2 as line abcfg. 5

While students of the social security program are well aware of the actuarial adjustment given to workers aged 62-64, many have expressed skepticism that it is actuarially fair. 6 To measure the extent to which the compensation actually is fair, 
we have made computations based on the law as it was in 1973, and life tables based on 1975, for a number of hypothetical individuals. Our calculations can be explained with reference to Figure 2. In this figure, the kinked budget constraint abcde simply duplicates Figure 1, and the hypothetical budget line abcfg indicates what a full actuarial compensation would create (distance $f d$ is equal to distance ab). Consider the decision to decrease leisure from $l_{0}$ to $l_{1}$ hours. With no actuarial offset, the individual would move from point $c$ to point $d$. With a full adjustment, he would move from point $c$ to point $f$ instead. With a partial adjustment, he would move to some intermediate point uch as $h$. Our calculations measure the distance dh as a fraction of the potential distance $d f=a b$. Thus a value of zero represents no actuarial adjustment, a value of unity represents a full adjustment, and so on.

The first two columns of Table 1 offer a selection of the many results we have obtained. There are several striking aspects. First of all, we have selected as our "base case" a representative 62-year-old: he is white and married, his wife is 59 years old, ${ }^{7}$ he has no dependent children, and his earnings history gives him average monthly earnings (AME) of \$436, an arbitrary but representative amount. For such a person, the adjustment is precisely actuarially fair at about a $5 \%$ interest rate--a figure that is quite high for a real after-tax interest rate. At more realistic (lower) interest rates, there is actually a considerable actuarial bonus for deferring benefits.

The story is only slightly less dramatic for an unmarried man. While the actuarial present value of the increase in his future benefits is smaller since he has no wife, so is the current benefit that he gives up. On balance, the actuarial offset is reduced somowhat. (Compare lines 1 and 2.)

The actuarial offset is smaller, however, if the wife is at least 65 or if there are dependent children. The reason is that no compensation is given for wives' or children's benefits that are lost when the worker foregoes one year's benefits 
Table 1

Degree of Actuarial Adjustment ${ }^{a}$

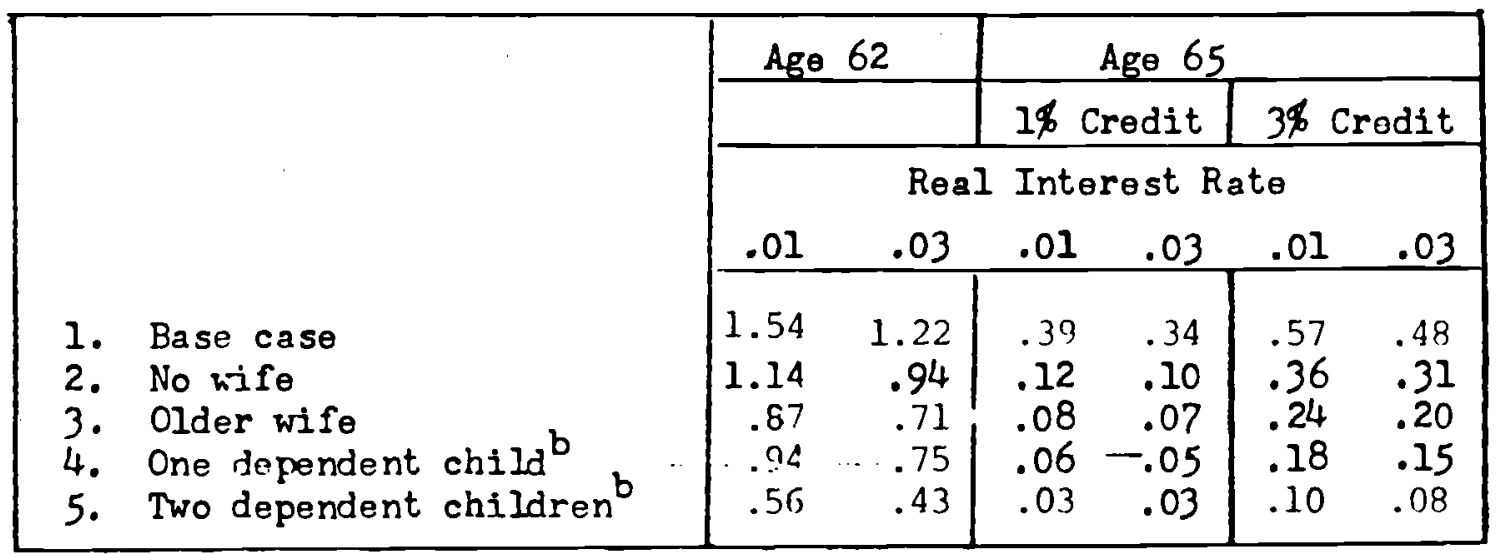

Notes:

a. Actuarial increase in future benefits as a fraction of maximum potential benefits at age 62 .

b. Same as base case, except children are 15 and 16; neither goes to college. 
by continuing to work. Lines $3-5$ in Table 1 show how the actuarial offset is reduced in several such cases. "Older wife" denotes a 62-year-old man with a 65-year-old wife. For him the actuarial adjustment is unfair, but still restores $71-87 \%$ of his lost benefits. ${ }^{8}$ The situation is quite similar for a 62-year-old man with a 59-yearold wife and a 15-year-old child ("one dependent child," line 4). For those few men of this age with two dependent children (line 5) the actuarial offset falls far short of being complete.

Things are quite different, however, for individuals aged 65 and over because, for them, the law makes no effort to give fair actuarial compensation for lost benefits. Instead, until the 1977 amendments to the social security law become effective, a token increase of $1 \%$ in future benefits is granted in any year in which the individual earns enough to lose all of his current benefits (i.e., works somewhere to the left of point $d$ ). This introduces an upward discontinuity into the budget constraint at point d. 9

That this $1 \%$ increase in benefits is quite inadequate is seen in the two middle columns of Table 1--which apply to a 65-year-old man. Except for the base case, the actuarial adjustment is trivial ( $12 \%$ or less). In the base case, however, the wife is under 65; so the offset, though incomplete, is not negligible because her benefits are essentially compensated in full. Just over one-third of lost benefita are recouped.

The 1977 amendments raise the $1 \%$ increase in future benefits to $3 \%$ beginning in 1981. As can be seen in the last two columns of Table 1, this reform will increase the actuarial adjustment, in our base case to around 50\%--thus negating about half of the apparent tax implied by the earnings test. Adjustments in other cases are smaller, with single men getting about a one-third offset and other groups getting still less. Our conclusions thus far seem to be as follows. For men aged 62-64 and eligible for partial benefits, the law provides actuarial compensation for those who 
postpone benefits that is typically fair or more than fair. This means that the effective budget constraint comes much closer to abcfg in Figure 2 than to abcde, so that the effective wage is essentially what it would have been in the absence of social security benefits. For men 65 and over, the actuarial offsets are far from complete, though the 1977 amendments will eventually make them restore perhaps 30-50\% of the lost benefits for a typical man.

\section{The Effect of Current Earnings on Future Benefits}

We have thus far argued that, when both the earnings test and the actuarial offsets are considered simultaneously, the social security law provides neither work incentives nor disincentives for 62-64-year-olds, but probably provides some disincentives for those 65 and older. We now turn to a rather neglected provision of the law which provides rather dramatic work incentives for almost all older workers.

The provision we have in mind is the automatic recomputation of benefits whenever current earnings rise above a certain amount. We first describe and evaluate how this mechanism operated prior to the 1977 amendments to the social security law-since this is the law that has applied to all men who have retired to date, and thus to all the recent econometric studies that have purported to detect a negative effect of social security benefits on the labor supply of older men. ${ }^{10}$ Once this discussion is complete, we consider how things were changed by the 1977 amendments. Automatic Benefit Recomputation (ABR)

To illustrate how automatic benefit recomputation (ARR) works, consider a man turning 65 in 1975. As noted above, the potential benefit for which he is eligible, B, depends on his earnings history, E, and on two principal demographic characteristics: whether he is married, and whether he has dependent children. It is calculated in steps. First, his earnings history is used to compute his Average Monthly Earnings (AME). The MME depends on the $T$ years of highest current earnings between 1951 and the current year, where the value of $T$ is the year in which the individual reached 
65. minus 1956. 11 Let the earnings history for those $T$ years be $\left(e_{1}, e_{2}, \ldots, e_{T}\right)$, and let $e_{\min }$ be the lowest of these. As soon as current earnings, $e_{0}$, exceed e $e_{\text {min' }}$ the automatic benefit recomputation provision (ABR) comes into play because $e_{0}$ replaces $e_{\min }$ in the earnings base used for computing benefits in future years. The effect of this replacement on AME is easy to calculate, as it depends only on the worker's age. For each dollar of earnings above $e_{\text {min' }}$ the AME increases by $1 / 12 \mathrm{~T}$ (the 12 converts annual earnings to moinly earnings). But what this increase in AME does to the individual's future benefits depends on several other factors. First, the individual's Primary Insurance Amount (PIA) depends on AME in a piecewise linear fashion, with the slope, JPIA/ DAME, depending on the worker's AME. 12 Next, the potential monthly benefit, $B / 12$, is defined as $B / 12=R(X) P I A$, where the factor of proportionality, $R$, depends on whether the individual has a wife and/or dependent children. 13

Thus the increase in annual benefits when current earnings increase by one dollar (assuming current earnings exceed $e_{\text {min }}$ ) is $\frac{\partial B}{\partial e_{0}}=\frac{1}{T} \rho(X) \frac{\text { AFIA }}{\partial A M E}$. Finally, the actuarial present value of this increase in annual benefits depends on the rate of discount and on any factor relevant to life expectancy (including the life expectancy of the wife, because of survivor's benefits).

The first important point to make is that automatic benefit recomputation has been of wide applicability. It is clear that most able-bodied men with normal work histories easily earned much more (in nominal dollars) at age 65 than they did in the worst of their previous best $T$ earning years. (That is, $e_{0}$ normally much exceeded $e_{\min }$.) So the effect was relevant to most workers and became operative at fairly low levels of work effort.

The second important. point is that the qualitative effect of the ABR can be quite impressive. For an individual turning 65 in 1975, $\mathrm{T}=19$, so each dollar of earnings above $e_{\min }$ adds $1 /(12 \times 19)=.0044$ to his $\mathrm{AME}$. Around the mean of the 
distribution of AME, DPIA/ $\partial \mathrm{AME}$ is about .45 , so the PIA increases by about. $.19 \phi$ for each dollar of additional earnings. If he is married, this increase in the PIA raises the monthly benefit check by .28ф, so the annual check goes up by $3.4 \phi$. While this may seem small, it must be remembered that this amount is to be received for as long as the individual lives, and then two-thirds of it is received for as long as the wife survives. For a $1 \%$ real interest rate and actual life expectancies, an actuarial present value calculation amounts to multiplying this anmal benefit of $3.4 \phi$ by a factor of about 16. The conclusion, therefore, is that the additional social security benefits attributable to the recomputation amount to about $54 \$$ for each dollar of earnings; that is, the marginal return to work effort is thereby increased by $54 \%$ of the wage rate. This is hardly a trivial effect, to say the least.

Since the value of benefits from $A B R$ is obviously sensitive to the discount rate used, this is an appropriate point to explain our use of such low discount rates. Note first that a real after-tax interest rate is appropriate, since social security benefits are indexed and tax free, and that such rates are historically very low. (Indeed, they are often negative.) Second, note that (except for issues of risk aversion) the probability that the individual might die is irrelevant to the choice of discount rate because survival probabilities are automatically incorporated in the actuarial present value calculations. Third, while high rates of subjective time preference are often confused with high rates of interest, only interest rates - are relevant to valuing streams of future income. Subjective time preferences come into play only in deciding how to consume the value of an asset over one's remaining lifet.jme. Even if older men have very high subject.ive discount rates, it would still be appropriate to use the low market interest rate unlnss these mon had drawn down all their other assets and were being constrained by an inability to borrow against future social security benefits. For all these reasons, we believe that a very low discount rate like $1 \%$ is most appropriate. 
The effective budget constraint created by the automatic benefit recomputation depends on the relationship between $e_{\min }$ and the exempt amount under the earnings test, $m$. Figure 3a, which is meant to represent a 65-year-old and ignores the actuarial adjustment mentioned in Section 2, illustrates a case where benefit recomputation comes into play only after the earnings test. Without recomputation, the budget constraint would be abcde. With it, the budge constraint is abcfgh. 14 In our illustrative example, the slope on $\mathrm{fg}$ is $w_{0}(1-t+.04)$, and the slope on gh is $w_{0}(1-t+.54)$. It, is clear that, while it is still possible for a utility maximizing worker to select point $c$, this choice is much less likely than it would appear to be under the conventional view that envisions a budget constraint like abcfde. Figure $3 b$ illustrates a case where $e_{\text {min }}$ falls below $m$, so that automatic benefit computation actually comes into effect before the earnings test. Here is seems quite unlikely indeed that social security would provide a work disincentive.

Now the se examples, while quite typical, are not of universal applicability. The magnitude of the wage subsidy implicit in ABR depends on the individual's age, his vintage, his marital status, his wife's age, whether he has dependent children, the level of his AME, his life expectancy (which varies with health and race), and how mich he plans to work in the future. ${ }^{15}$

Two questions naturally arise about the population of potential social security recipients in the United States. First, what has the actual distribution of emin values looked like? This governs how many people can take advantage of benefit recomputation. Second, how large have the wage subsidies implicit in ABR been for actual workers?

Evidence from the Retirement History Survey

To answer these questions we have done extensive calculations based on actual individuals in the Longitudinal Retirement History Survey (IRHS). We consjdered each of the 907 men in the IRHS who turned 65 in 1975. From each man's social security earnings history and demographic data, it was possible to calculate precisely both 
the level of earnings at which $A B R$ came into play (e min) and the magnitude of the implicit wage subsidy. Tables 2 and 3 summarize the results.

Look first at columns (1) and (2) in Table 2, which indicate how common automatic benefit recomputation has been in practice. About $24 \%$ of married men and $32 \%$ of single men were eligible for an implicit wage subsidy from ABR on their very first dollar of earnings $\left(e_{\min }=0\right.$ ) because they had not worked in covered employment for $T$ years. Virtually $100 \%$ of the sample would have been able to receive ABR before they earned $\$ 5,000$. For reference, average anmual earnings of all private nonfarm workers in the U.S. in 1975 exceeded $\$ 8,000$. Another way to put these results into perspective is to note that the exempt amount of earnings under the social security law, denoted $m$ above, was $\$ 2,520$ in 1975 . Thus for almost half of all workers the wage subsidy from $A B R$ became relevant before the tax from the earnings test, so that Figure $3 b$ rather than Figure $3 a$ was relevant.

The next question is how large the implicit wage subsidies implied by automatic benefit recomputation actually are. Table 3, which contains the principal results of this paper, tabulates the frequency distribution of this subsidy expressed as a percentage of the current wage. For the most part the calculations use the 1 percent discount rate that we find most realistic. However, for those who prefer a higher rate, we also show results based on a $5 \%$ discount rate. Each column in ti.e table is a frequency distribution. Thus, for example, with a $1 \%$ discount rate and the 1975 law, column (1), 42.4\% of married mon had subsidy rates between $55 \%$ and $60 \%$, $33.1 \%$ had subsidy rates brtween $50 \%$ and $55 \%$, and so on.

The results in columns (1)-(3) are quite striking. Implicit subsidy rates for married men average about 54\%, with most concentrated in the 50-60\% range. 16 Thus benefit recomputation just about offsets the tax implicit in the earnings test. Even at a $5 \%$ discount rate, which we view as far too high, most married men still had 
Tajle 2

Districution of e min

\begin{tabular}{|c|c|c|c|c|}
\hline \multirow[b]{2}{*}{ Value of $\theta_{\min }$} & \multicolumn{4}{|c|}{$\begin{array}{l}\text { Percentage of men reaching } 65 \text { in 1975: } \\
\text { Under } 1975 \text { law After } 1977 \text { Amendments }\end{array}$} \\
\hline & $\frac{\text { Marjizd }}{(I)}$ & $\frac{\text { Single }}{(2)}$ & $\frac{\text { Married }}{(3)}$ & $\frac{\text { Single }}{(4)}$ \\
\hline$\theta_{\min }=0$ & 23.5 & 32.4 & 23.5 & 32.4 \\
\hline $0<e_{\min }<600$ & 4.3 & 5.2 & 3.4 & 3.7 \\
\hline $600 \leq \mathrm{e}_{\min }<1,200$ & 4.5 & 6.6 & 3.0 & 6.6 \\
\hline $1,200 \leq \mathrm{e}_{\min }<1,800$ & 6.9 & 5.2 & 4.4 & 3.7 \\
\hline $1,800 \leq \theta_{\min }<2,400$ & 5.2 & 8.8 & 4.3 & 5.2 \\
\hline $2,400 \leq \theta_{\min }<3,000$ & 5.6 & 8.8 & 3.1 & 0 \\
\hline $3,000 \leq \mathrm{e}_{\min }<3,600$ & 7.8 & 4.4 & 2.9 & 4.4 \\
\hline $3,600 \leq \mathrm{e}_{\min }<4,200$ & 20.5 & 15.4 & 3.3 & 7.4 \\
\hline $4,200 \leq \mathrm{e}_{\min }<4,800$ & 19.1 & 13.2 & 4.0 & 4.4 \\
\hline $4,800 \leq \theta_{\min }<5,400$ & 2.5 & 0 & 4.3 & 3.0 \\
\hline $5.400 \leq \theta_{\min }<6.000$ & 0 & 0 & 5.2 & 3.0 \\
\hline $6,000 \leq \mathrm{e}_{\min }<6,600$ & 0 & 0 & 22.4 & 15.4 \\
\hline $6,600 \leq{ }_{\min }<7,200$ & 0.1 & 0 & 14.9 & 11.0 \\
\hline $\mathrm{e}_{\min } \geq 7,200$ & 0.1 & 0 & 1.4 & 0 \\
\hline Mean value & $\$ 2.378$ & $\$ 1,841$ & $\$ 3.738$ & $\$ 2,904$ \\
\hline Sample size & 771 & 136 & 771 & 136 \\
\hline
\end{tabular}

a) $e_{\min }$ is the lowest annual earnings figure in the earnings base used to compute AME for the 1975 law or ADE for the post-1977-amendments law. 
Taols 3

Distribution of Implicit Wage Subsidy Rates

Due to Automatic Zenefit Recomputation

\begin{tabular}{|c|c|c|c|c|c|c|}
\hline \multirow[b]{3}{*}{$\begin{array}{l}\text { Implictt } \\
\text { Subsidy } \\
\text { Rate }(\%)\end{array}$} & \multicolumn{6}{|c|}{ Percentaze of zen reaching 65 in 1975: } \\
\hline & \multicolumn{3}{|c|}{ Under 1975 Lä } & \multicolumn{3}{|c|}{ After 1977 Amendments } \\
\hline & $\begin{array}{l}\text { Married } \\
\frac{1 \% \text { Rate }}{(1)}\end{array}$ & $\begin{array}{l}\text { Married } \\
\frac{58 \text { Pate }}{(2)}\end{array}$ & $\begin{array}{l}\text { Single } \\
\frac{10 \text { Rate }}{(3)}\end{array}$ & $\begin{array}{l}\text { Married } \\
\frac{1 \% \text { Rate }}{(4)}\end{array}$ & $\begin{array}{l}\text { Married } \\
\frac{5 \% \text { Rate }}{(5)}\end{array}$ & $\begin{array}{l}\text { Single } \\
\frac{1 \% \text { Rate }}{(6)}\end{array}$ \\
\hline $0-5$ & 8.6 & 8.6 & 15.4 & 11.3 & 11.3 & 22.8 \\
\hline $5-20$ & 0 & 0.4 & 0.7 & 1.0 & 1.2 & 0 \\
\hline $20-25$ & 0 & 0.7 & 0 & 0.1 & $12 \cdot 5$ & 75.0 \\
\hline $25-30$ & 0.3 & 0.4 & 77.9 & 0.4 & 72.2 & 0.7 \\
\hline $30-35$ & 0.5 & 10.6 & 2.2 & 3.9 & 0.4 & 0.7 \\
\hline $35-40$ & 0.3 & 70.2 & 1.5 & 54.1 & 0.7 & 0 \\
\hline $40-45$ & 0.9 & 4.9 & 0.7 & 25.6 & 0.1 & 0 \\
\hline $45-50$ & 2.9 & 0.1 & 0 & 1.2 & 0 & 0 \\
\hline $50-55$ & 33.1 & 0.5 & 0 & 0.5 & 0 & 0 \\
\hline $55-60$ & 42.4 & .0 .3 & 0 & 0.1 & 0 & 0.7 \\
\hline$-60-65$ & 4.5 & 0.1 & 0 & 0.1 & 0.3 & 0 \\
\hline $65-70$ & 2.2 & 0 & 0 & 0 & 0 & 0 \\
\hline $70-100$ & 1.2 & 0.8 & 1.5 & 0.1 & 1.4 & 0 \\
\hline Over 100 & 3.2 & 2.5 & 0 & 1.6 & 0 & 0 \\
\hline Mean & 54.3 & 36.0 & 25.6 & 35.7 & 23.7 & 16.2 \\
\hline Sample size & 771 & 771 & 136 & 771 & 771 & 136 \\
\hline
\end{tabular}


implicit subsidy rates between 35 and $40 \%$. Single men receive only about half this subsidy rate, however.

The conclusion, then, is that our illustrative example is indeed representative of the situation that has faced the vast majority of married men who reached retirement age during the 1970s. The automatic benefit recomputation certainly has been no mere detail.

It is, however, worth paying some attention to the tails of the distributions in Table 3. Looking first at the lower tail, we note that $9 \%$ of married men and about 15\% of single men get no benefit recomputation at all. These individuals are at the minimum PIA, so their benefits are independent of current earnings at the margin. For this minority, budget constraint abcde in Figure $3 a$ is a fairly accurate representation of their choice set, and so work disincentives are likely. At the other extreme, however, we find that about it percent of married men and about 1.5 percent of single men turning 65 in 1975 experienced implicit wage subsidies greater than 70 percent: This is an extremely large "wedge" which should have had a correspondingly large incentive effect on their labor supply.

One further characteristic of the automatic benefit recomputation (ABR) merits consideration. The actuarial present value of any increase in future social security benefits obviously depends on age. All the calculations in Table 3 are based on 65-year-olds. If we considered these same individuals at a younger age, the annual flows of future benefits from $A B R$ would be identical, but the discount factors needed to convert those flows to an equivalent current wage subsidy would be greater. Thus the implicit subsidy rate is lower at younger ages, which provides an incentive to shift labor supply to older ages--exactly the opposite of the assumption made by Burkhauser and Turner (1978).

:For men older than 65 , however, potential benefits always start "next year," so the number of years over which benefits can be received falls, thus reducing the 
implicit subsidy. For example, the average subsidy rate for married men using a $1 \%$ discount rate falls from $54 \%$ at age 65 , to $44 \%$ by age 69 and $34 \%$ by age 73 . Thus the subsidy rate peaks at age 65 .

Combining both of these cases, it seems that the automatic benefit

recomputation provision, considered in isolation, provides some incentive to concentrate work effort around age 65. As we have seen earlier, however, the actuarial of fsets to the earnings test are normally fair before age 65 and unfair thereafter. So it seems that when both factors are considered social security provides the strongest work incentives for individuals aged 62-64--precisely the group that many have claimed are induced to retire prematurely by social security:

The 1977 Social Security Amendments

In 1977 many aspects of the social security law were revamped, and one of these changes affected automatic benefit recomputation in an important way. Prior to the 1977 amendments, the AME was based on the nominal earnings history. Since the 1977 amendments, covered earnings through age 60 have been indexed to average earnings in the year in which the individual turns 60. Thus, for example, if a nominal earnings figure like $\$ 1,600$ from some past year j.s included in the earnings base, but average wages have tripled between that year and the year in which the individual turns 60 , then $\$ 4,300$ is used in computing Average Indexed Monthly Earnings (AIME). Earnings after age 60 are included without indexing, just as before.

This element of indexing has a clear effect on the likelihood that any particular individual will be subject to automatic bonefit recomputation: it lowers the chances by substantially reducing the gap betwoen "old earnings" and "current earnings" for most people. In addition, for those who remain subject to ABR, the implicit subsidy rates were reduced by the 1977 amendments because the amendments, while raising typical AIME values by indexing, simultaneously reduced the slope coefficients $\mathrm{APIA} / \mathrm{AME}$. For most people, this reduction was about one-third, indicating a one-third reduction in the typical subsidy rate. 
Nonetheless, due to the combined effects of inflation since age 60 and the normal life-cycle pattern in earnings, most older workers are still able to earn much more than $e_{\min }$ by working close to full time. On balance, then, while the 1977 amendments will reduce both the fraction of the population subject to $A B R$ and the typical wage subsidies that it provides, it still seems likely that a large number of older workers will receive sizeable implicit wage subsidies through ABR.

Since the 1977 amendments are not yet fully effective, we have no actual sample of potential retirees whose subsidy rates we can compute. Our approach was to pretend that, the 1977 amendments had been in effect in 1975, the year our sample of men reached age 65. We computed AIME for each man, applying indexing as prescribed in the 1977 amendments, ${ }^{17}$ and repeated the calculations discussed earlier. By doing so, we get a quantitative "feel" for the changes in ABR wrought by the amendments.

As columns (3) and (4) of mable 2 point out, the distribution of $e_{\text {min }}$ is pushed "outward" (compare columns (1) and (2). The most common values of emin for married men, for example, would have been in the $\$ 6,000-\$ 7,200$ range with indexing instead of in the $\$ 3,600-\$ 4,800$ range. Clearly this means that some workers that were eligible for benefit rocomputation without indexing would not have been eligible if indexing had been in effect. The mean value of emin would have been increased $57 \%$ by indexing. Note, however, the obvious point made by the top row of Table 2 : indexing has no effect whatever on the substantial minority of men whose 'min's are zero because they lack sufficient years of covered earnings. And when we remember that average annual earnings in 1975 exceeded $\$ 8,000$, it becomes clear that a great many workers would have been elipible for $A B R$ even with indexing.

Turning next to columns (4)-(6) of Table 3, we see that the wage subsidy rates implicit in automatic benefit recomputation would have been reduced by about one-third by indexing, just as suggested. Nonetheless, this still leaves the average subsidy rate for married men at about $36 \%$ (assuming a $1 \%$ discount rate), and assigns 
subsidy rates in the $35-45 \%$ range to about $80 \%$ of all married workers.

Thus even when the 1977 amendments become fully effective, automatic benefit recomputation will still provide large wage subsidies to most workers. Interaction with Supplemental Security Income (SSI)

One final proviso about recent revisions in the law. Since 1975, individuals with poor earnings histories have been eligible to draw benefits from Supplemental Security Income (SSI) that exceed the benefi亡s they would be entitled to under the standard social security program. For these individuals, who now comprise about oneeighth of all social security recipients, automatic benefit recomputation is irrlevant. Thus some of the low income people that would have faced huge wage subsidies from $A B R$ prior to the advent of SSI (the upper tails of the distributions in Table 3) no longer have this strong work incentive.

\section{Summary and Conclusions}

The main findings of this short paper are easy to summarize:

1. The earnings test for social security does not present a work disincentive for the typical worker aged 62-64 because, if he loses benefits to the earnings test, he recoups most or even more than all of them through an actuarial adjustment of his future benefits. There are, however, exceptions to this--especially those few men of this age who have dependent children.

2. At least prior to the 1977 amendments and the advent of SSI, the vast - majority of workers became subject to automatic benefit recomputation at rather low levels of work effort. This provision provided an implicit wage subsidy of $50-60 \%$. about the same as the tax rate in the earnings test, and it romained in effeot over a much broader range of earnings.

3. Because of these two effects, and especially the latter, it seems likely that the social security law--if understood by the public--should provide work disincentives for only a small minority of individuals. It seems that social security should induce the majority of older workers to work harder. ${ }^{18}$ 
4. Recent changes in the law, especially SSI and the indexing provisions in the 1977 amendments, will reduce the importance of automatic recomputation, though it still seems likely that most individuals working close to full time will be subject to it. Wage subsidies implicit in the benefit recomputation will be about two-thirds as large as they were in the 1970s.

5. Social security no doubt distorts labor-lei sure choices in many complex ways, and therefore creates a variety of deadweight losses. But the glib assertion that these distortions typically amount to powerful work disincentives is just that-a tlib assertion.

These findings, in turn, lead us to two sorts of conclusions--one aimed at scholars doing research on the effects of social security, and the other aimed at policymakers.

6. Since a full understanding of the complex nature of the social security law shows that it does not provide significant work disincentives for many people, the many recent, econometric findings that social security reduced labor supply and/or : encouraged retirement are surprising, to say the least. 19 The approaches used in econometric studies of the labor supply effects of social security need rethinking. and will probably have to be much more complicated than those that have been used to date.

7. In discussing automatic benefit recomputation with knowledgeable governiuent officials and academic researchers, we learned that while almost everyone knew that the provision existed, almost no one had any idea of its quantitative importance. Furthermore, the nature of the reconputation is clearly complex. These two facts suggest to us that many pooplo eligj.bln for social socurity benerits may not understand how their current earnings affect their future benefits. It is possible, therefore, that social security is discouraging labor supply only because its provisions are poorly understood. If this hypothesis is correct, then one simple way to cure any "disincentive" effects that social security may now be having on the labor supply decisions of older 
workers is simply to tell these workers how the law really works: Happily, this policy initiative is non-partisan and non-ideological, requires no legislation, and should entail negligible budgetary expense. A good policy, it would seem.

However, a broader policy issue can be raised. According to our arguments, social security is probably distorting the labor-leisure decisions of most older workers in the direction of greater work effort. This is particularly true of those between 62 and 64 years of age, who on balance typically receive a $50 \%$ wage subsidy. It is not clear what social purpose is served by this distortion. 
Michael J. Boskin, "Social Security and Retirement Decisions," Economic Inquiry, Jamary 1977.

and Michael D. Hurd, "The Effect of Social Security on Early Retirement," Journal of Public Economics, December 1978.

Richard V. Burkhauser, "An Asset Maximization Approach to Early Social Security Acceptance," Discussion Paper 463-77. Institute for Research on Poverty, University of Wisconsin, Madison, 1977.

and John A. Turner, "A Time-Series Analysis on Social Security and it.s Effect. on the Market Work of Men at Younger Ages," Journal of Political Economy. August 1978.

Anthony J. Fellechio, "The Social Security Earnings Test, Labor Supply Distortions, and Foregone Payroll Tax Revenue," National Bureau of Economic Research Working Paper No. 272, August 1978.

Joseph P. Quinn, "Microeconomic Determinants of Early Retirement: A CrossSectional View of White Married Men," Journal of Human Resources, Summer 1977. 


\section{FOOTNOTES}

I Boskin (1977), Quinn (1977), Boskin and Hurd (1978), Burkhauser (1977), and Pellechio (1978).

2 The same formula holds for women, but to date most married women have been able to collect more as wives ( 50 percent of their husband's benefits) than they could based on their own work histories. Hence our focus on men.

3 For simplicity, it is assumed that social security benefits constitute the only source of non-labor income, and income taxes are ignored.

It We have discovered some bunching at this point in our studies with the Longitudinal Retirement History Survey (IRHS).

5 Actually, future benefits, rathor than increasing continually as current earnings are withheld, jump to of fset a month's lost benefits whenever any benefits are withheld in that month.

${ }^{6}$ See, for example, Burkhauser (1977), pp. 5-6.

7 The wife is assumed to register for benefits as soon as she is eligible.

8 Here, and in what, follows, we assume that a discount rate in the $1-3 \%$ range is most reasonable.

${ }^{9}$ A further complicating distortion in the pre-1977 law is that workers who had received partial benefits prior to age 65 were not eligible for this $1 \%$ increase.

${ }^{1.0}$ See footnote 1.

${ }^{11}$ The formula for computing $T$ varies depending upon the year the individual reaches age 62. For individuals reaching age 62 in 1973 or 197., T is set to 19. For individuals reaching 62 in 1975 or later, the formula is as described in the text except that the year the individual reaches age 62 is used instead of the year the individual reaches age 65.

${ }^{12}$ Since the FIA formula is redistributive, this slope generally declines as we meve to hipher AMi brackets. However, there is a minimum PIA. For workers with very poor earnings histories the slope will therefore be zoro. 
${ }^{13}$ Specifically, B is 1.0 for a single man with no dependent children, 1.5 for a married man whose wife also starts receiving benefits at 65 , and 0.5 higher for each dependent child--subject to a maximum family benefit which is a piecewise linear function of PIA. There are corresponding rules for determining the $B$ factors for survivors.

14 For a minority of relatively high-wage workers, the current social security earnings ceiling will be reached somewhere on line segment gh. At this point, the recomputation would cease being relevant and the slope would return to the explicit wage. The payroll tax also ends at this point.

${ }^{15}$ The last factor is relevant to when he will actually receive the increased benefits derived from $A B R$. In all our computations we assume that the worker begins to receive full social security benefits (i.e., earns less than $m$ ) starting "next year."

16 We also made computations for a sample of married men retiring in 1971 . Because of the different law in effect then, the distribution of subsidy rates was a bit. lower, averaging $49 \%$.

17 The dellar figures in the 1977 formulas were reduced, however, based on the size of average earnings in 1975 compared with 1979, the year the new law first went into effect.

18 For the early generations of retires under social security, there was a substantial net transfer payment that may have induced earlier retirement through income effects. These net transfers, however, have been declining in the recont past.

19 A partial list of such studies apprared in footnote 1 . 